\title{
Modelling the Process of Processing Ash and Slag Wastes of TPP by Means of Consistent Application of CAE- and CAD- systems
}

\author{
Olesya Aksenova ${ }^{1}$, Evgenia Nikolaeva ${ }^{1}$, and Ibodat Haldybaeva ${ }^{2}$ \\ ${ }^{1}$ EDP Sciences, T.F. Gorbachev Kuzbass State Technical University, Underground Mining \\ Department, 650000 Kemerovo, 28 Vesennya st., Russian Federation \\ ${ }^{2}$ Tashkent State Technical University named after Islam Karimov, 100097, 2, Universitetskaya st, \\ Tashkent, Uzbekistan
}

\begin{abstract}
The article considers the possibility of joint application of mathematical processing and computer 3D modeling of the technological process line for processing ash and slag waste from thermal power plants (TPP). The authors suggest considering an approach to the design of the ash and slag waste processing site by mathematical processing and 3D computer modeling. The mathematical processing with the help of Enetwork device and the creation of a 3D model allows to plan the site for processing ash and slag waste, select the appropriate technology and thereby ensure the environmental effect of both existing and projected power plants. The authors present the results of processing the technological process of recycling ash and slag wastes of TPP in terms of E-networks using mathematical processing in the Simulink application, which displays the device model from the standard blocks available in the program and performs the necessary calculations. 3D models of individual equipment units selected on the basis of mathematical processing calculations in the Simulink application, were created using computer 3D modeling in a graphical editor. A 3D visualization of the technological section of ash and slag waste processing was performed, which allows to clearly show the planned section at the design stage, which, if necessary, will allow to easily make changes to the project.
\end{abstract}

\section{Introduction}

Currently, the problem of utilization of ash and slag wastes (ASW) is relevant. During the operation of the TPP, more than $10 \%$ of the processed coal goes to waste. Today, a small part of the ASW is being utilized. In the process of recycling, wall cinder blocks and paving slabs are produced.

In Russia, there are more than one hundred thermal power plants, their ash dumps are filled with ASW, and the expansion of such dumps is impossible and has a negative impact on the environment. About thirty million tons of ash and slag are produced each year.

ASW are a secondary resource, and they should be considered as technogenic mineral deposits (TMD). ASW have physical and chemical properties that are economically appro- 
priate to be used in various industries (construction, national economy, etc.). In the process of recycling ASW we receive expensive materials and products (Fig. 1).

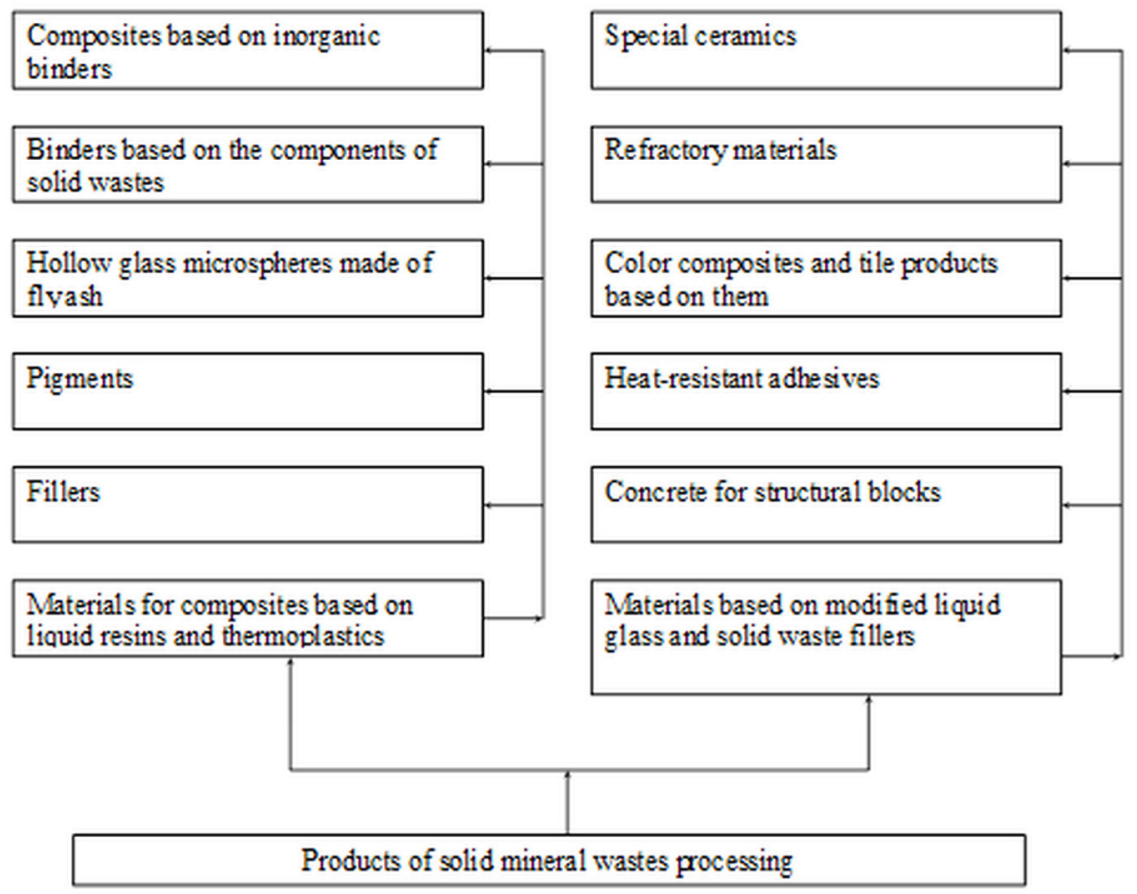

Fig. 1. Products of ASW recycling.

The paper considers a technological process consisting of several cycles of ASW disposal. Under the cycle, we will understand a certain process as a result of which you can get products ready for sale.

\section{Materials and Methods}

There are a number of technologies of ASW recycling. The authors model the process of ASW recycling in sequence in CAE- and CAD- systems, the schematic diagram of this process is shown in Figure 2.

The whole technological process of ASW recycling includes:

- heap leaching, the result is rough gold and silver;

- $\mathrm{SiO} 2$ sintering in a reverberatory furnace, resulting in raw materials for making liquid glass $(\mathrm{SiO} 2)$ and raw materials for aluminum sulfate coagulant;

- production of liquid glass;

- production of construction materials;

- manufacturing of the aluminium sulphate coagulant and the extraction of gallium;

- extraction of titanium, tantalum, niobium, cerium, yttrium, thorium, uranium oxides and zirconium concentrates with hafnium.

At the stage of planning the processes of fuel and energy complexes and developing technical documentation, a modern range of computer programs allows to present an analysis of the future TPP operation from different sides. Mathematical modeling [8-15] makes it possible to check the correctness of the model making and its correction at the construction 
stage, three-dimensional computer modeling allows to get a realistic image based on the available technical documentation, identify technical errors and make adjustments at the planning stage of individual technological processes and TPP as a whole.

When conducting mathematical analysis, it is advisable to use the E-network apparatus $[1,2]$. E-networks are essentially a generalization of Petri nets, they are a graphical and mathematical apparatus for modeling various systems.

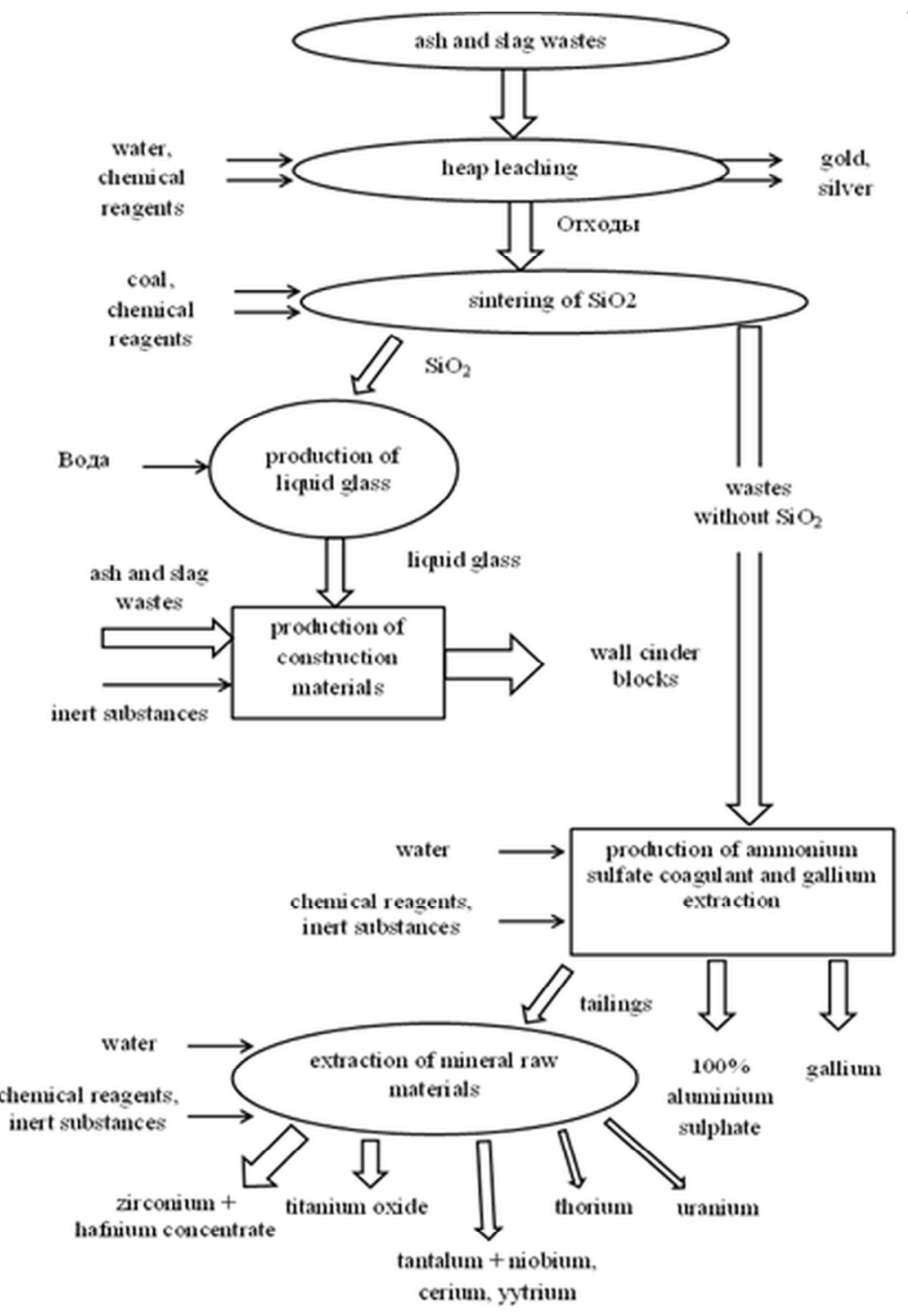

Fig. 2. Scheme of the technological process of ASW recycling.

The abstract model of TPP with the possibility of its extension is under discussion in this paper. A model of the technological process of ASW recycling in terms of E-networks is presented in Fig. 3. 


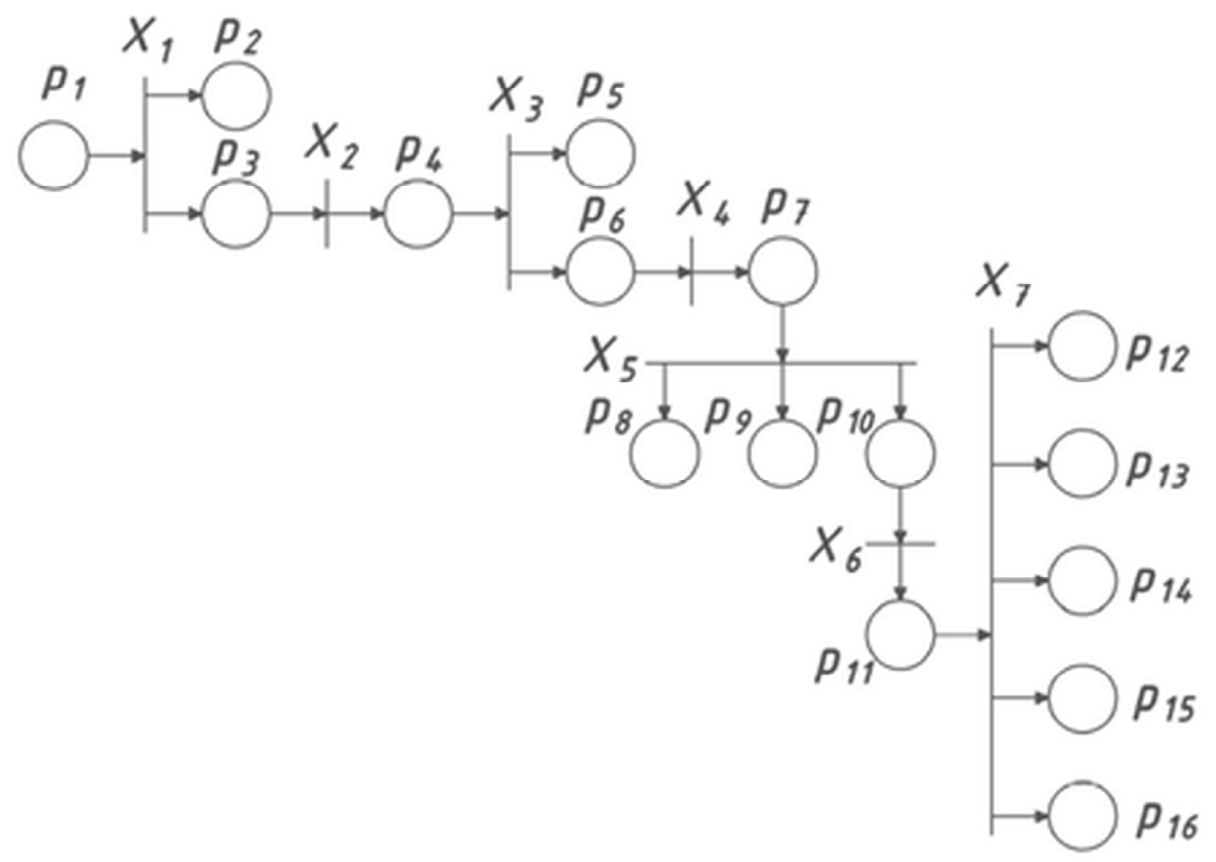

Fig. 3. The process of ASW recycling in terms of E-networks.

We introduce the notations:

$\mathrm{p}_{1}$ - ASW got to the system of recycling;

$\mathrm{p}_{2}$ - rough gold and silver is received;

$\mathrm{p}_{3}$ - intermediate wastes are obtained;

$\mathrm{p}_{4}$ - intermediate wastes are collected in reverberatory furnace;

$\mathrm{p}_{5}$ - liquid glass is produced;

$\mathrm{p}_{6}$ - wastes released from silicon dioxide are obtained;

$\mathrm{p}_{7}$ - wastes got at the leaching unit;

$\mathrm{p}_{8}$ - aluminum sulfate coagulant is obtained;

$\mathrm{p}_{9}$ - gallium is extracted;

$\mathrm{p}_{10}$ - intermediate wastes are obtained;

$\mathrm{p}_{11}$ - intermediate wastes got to the system consisting of two special reactors;

$\mathrm{p}_{12}$-uranium is obtained;

$\mathrm{p}_{13}$-thorium is formed;

$\mathrm{p}_{14}$ - tantalum, niobium, cerium and yttrium are formed;

$\mathrm{p}_{15}$ - titanium oxide is obtained;

$\mathrm{p}_{16}$ - concentrate of zirconium and hafnium is obtained;

$\mathrm{X}_{1}=\left(\mathrm{F}, 0, \varphi_{1}\right)$-heap leaching process;

$\varphi_{1}=\mathrm{L}\left(\mathrm{X}_{1}\right)=\left\{\mathrm{p}_{1} \mathrm{X}_{1} \mid \mathrm{X}_{1} \rightarrow \mathrm{p}_{1} \mathrm{p}_{2} \mathrm{p}_{3}\right\}=\left\{\mathrm{p}_{1} \mathrm{p}_{2} \mathrm{p}_{3}\right\} ;$

$\mathrm{X}_{2}=\left(\mathrm{T}, 0, \varphi_{2}\right)$ - transfer of the wastes into reverbaratory furnace;

$\varphi_{2}=\mathrm{L}\left(\mathrm{X}_{2}\right)=\left\{\mathrm{p}_{3} \mathrm{X}_{2} \mid \mathrm{X}_{2} \rightarrow \mathrm{p}_{3} \mathrm{p}_{4}\right\}=\left\{\mathrm{p}_{3} \mathrm{p}_{4}\right\}$

$\mathrm{X}_{3}=\left(\mathrm{F}, 0, \varphi_{3}\right)-$ the sintering process of silicon dioxide;

$\varphi_{3}=\mathrm{L}\left(\mathrm{X}_{3}\right)=\left\{\mathrm{p}_{4} \mathrm{X}_{3} \mid \mathrm{X}_{3} \rightarrow \mathrm{p}_{4} \mathrm{p}_{5} \mathrm{p}_{6}\right\}=\left\{\mathrm{p}_{4} \mathrm{p}_{5} \mathrm{p}_{6}\right\}$;

$\mathrm{X}_{4}=\left(\mathrm{T}, 0, \varphi_{4}\right)-$ transfer of the wastes into the leaching unit;

$\varphi_{4}=\mathrm{L}\left(\mathrm{X}_{4}\right)=\left\{\mathrm{p}_{6} \mathrm{X}_{4} \mid \mathrm{X}_{4} \rightarrow \mathrm{p}_{6} \mathrm{p}_{7}\right\}=\left\{\mathrm{p}_{6} \mathrm{p}_{7}\right\}$; 
$\mathrm{X}_{5}=\left(\mathrm{F}, 0, \varphi_{5}\right)-$ the process of producing aluminum sulfate coagulant and extracting gallium using a leaching unit and a reactor;

$\varphi_{5}=\mathrm{L}\left(\mathrm{X}_{5}\right)=\left\{\mathrm{p}_{11} \mathrm{X}_{5} \mid \mathrm{X}_{5} \rightarrow \mathrm{p}_{7} \mathrm{p}_{8} \mathrm{p}_{9} \mathrm{p}_{10}\right\}=\left\{\mathrm{p}_{7} \mathrm{p}_{8} \mathrm{p}_{9} \mathrm{p}_{10}\right\}$

$\mathrm{X}_{6}=\left(\mathrm{T}, 0, \varphi_{6}\right)$-transfer of the wastes;

$\varphi_{6}=\mathrm{L}\left(\mathrm{X}_{6}\right)=\left\{\mathrm{p}_{10} \mathrm{X}_{6} \mid \mathrm{X}_{6} \rightarrow \mathrm{p}_{10} \mathrm{p}_{11}\right\}=\left\{\mathrm{p}_{10} \mathrm{p}_{11}\right\}$;

$\mathrm{X}_{7}=\left(\mathrm{F}, 0, \varphi_{7}\right)$ - the process of extraction of mineral raw materials in the two reactors;

$\varphi_{7}=L\left(X_{7}\right)=\left\{p_{11} X_{7} \mid X_{7} \rightarrow p_{11} p_{12} p_{13} p_{14} p_{15} p_{16}\right\}=\left\{p_{11} p_{12} p_{13} p_{14} p_{15} p_{16}\right\}$.

To implement the built model of the E-network on the computer [5], the application Simulink [4] realized in the environment MatLab [1,3] was used (Fig. 4.).

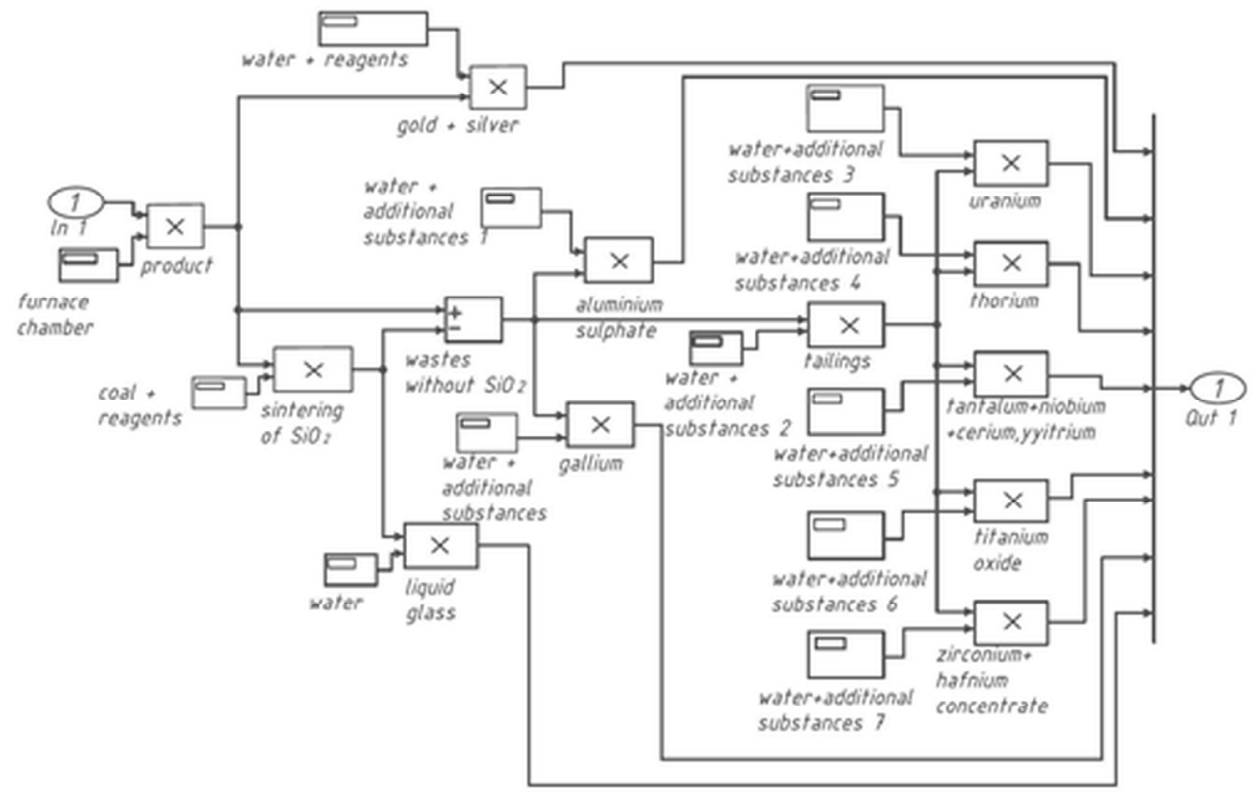

Fig. 4. Implementation of the recycling process in the environment Simulink.

\section{Results and Discussion}

When modeling in Simulink, it is important that all blocks can be selected from the library and used to create the necessary model and perform calculations. These principles of visual programming allow one not to learn programming languages and numerical methods of mathematics, but simply use them as built-in tools. Being a specialist in its subject area, you can easily assess the correctness of the calculations.

The model created in Simulink is a balance model of material flows [6, 7], consisting of several technological stages: loss of coal during its preparation for combustion; generation of electricity; formation and processing of ash and slag waste; formation and cleaning of gas waste. For the sake of clarity of the balance model and convenience of its expansion, the processing and cleaning blocks were implemented as subsystems. As an example of mathematical processing and three-dimensional computer modeling, the subsystem for processing ASW is presented in more detail.

Creation of a three-dimensional model or 3D modeling of an object allows to develop a visual volumetric image of the object, and the process of creating photorealistic images based on three-dimensional model of the object allows to obtain the $3 \mathrm{D}$ visualization. In 
addition, it allows to clearly see technical flaws in the theoretical planning and eliminate them.

The process of modeling and visualization of any object or process includes several operations: creating a three-dimensional model of the object, texturing, lighting, animation, and rendering.

According to the stages of the modeling process and the initial data, the models of the parts included in the assembly units were developed in the graphic editor, from which the technological line of the ASW recycling system was made. Then the assembly units were put together and the texture was applied. The example of 3D modeling of a separate assembly unit included in the technological line is shown in figures 5 and 6.

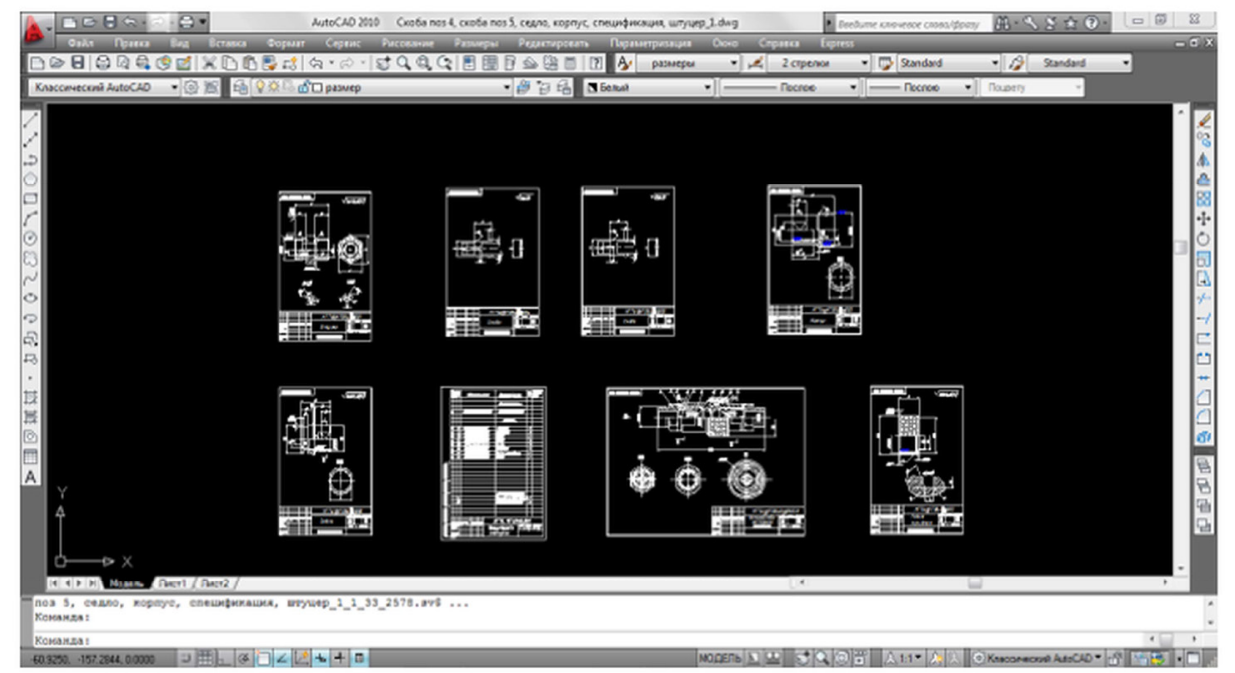

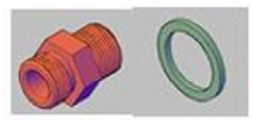

1

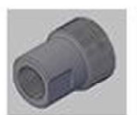

3

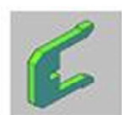

4

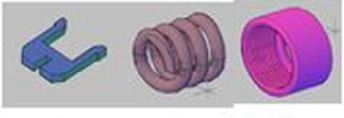

7

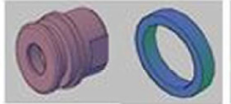

8

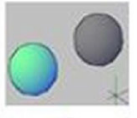

10

Fig. 5. Modeling parts included into an assembly unit (1-fitting, 2-gasket, 3-housing, 4-bracket, 5bracket, 6-spring, 7 - cap nut, 8-seat, 9-ring, 10-balls).
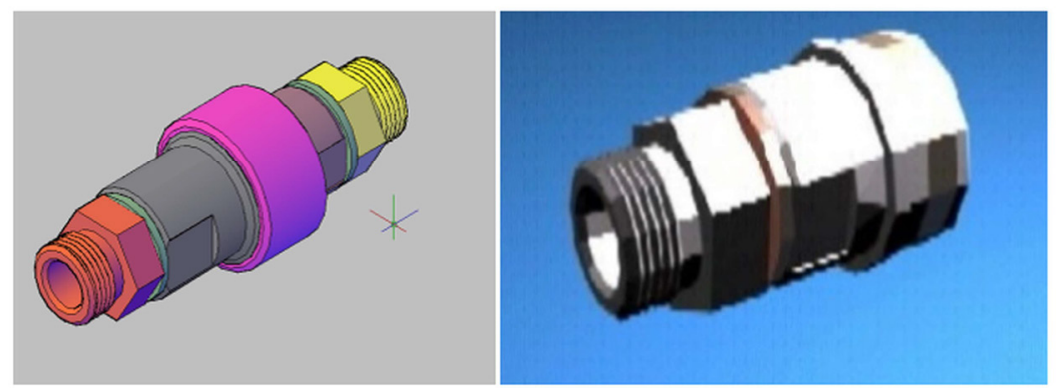

Fig. 6. Three-dimensional image of an assembly unit of equipment. 
Next, solid-state models of the equipment and pipelines were constructed, then a threedimensional image of the future process line was made taking into account the planned design area and the equipment placement (Fig. 7).

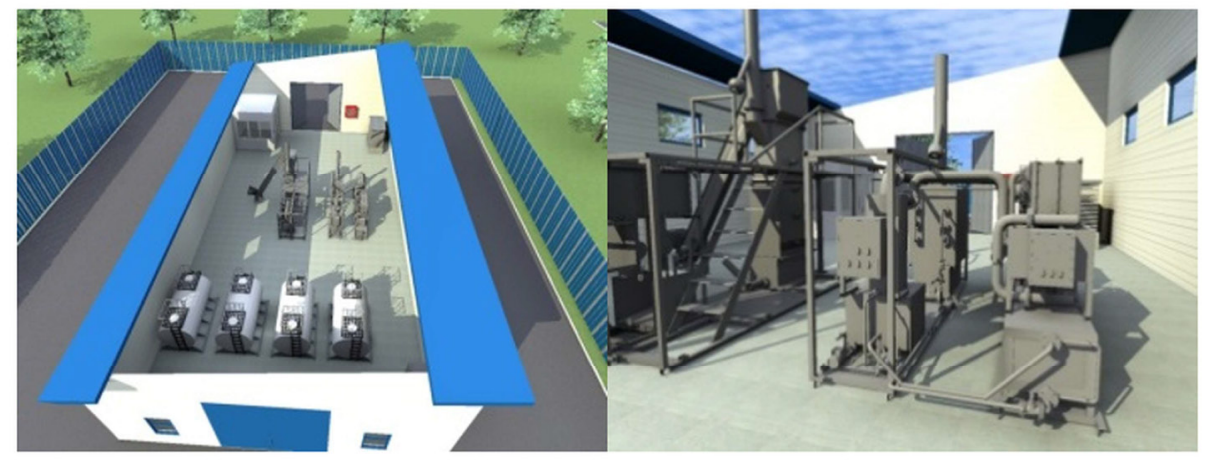

Fig. 7. Three-dimensional model of ASW recycling system.

In conclusion, it should be noted that the resulting model can be further expanded by adding the necessary modules to its structure.

\section{Conclusions}

The problem of using mathematical processing and computer modeling tools in planning the working processes of a power plant ASW recycling system at the stage of planning and designing a TPP has been analyzed. Optimization of planning of the ASW recycling system by means of mathematical processing and computer modeling is proposed, which can allow to evaluate the planned result, select the production technology, and ensure a high positive environmental effect of the planned ASW recycling system. The paper presents the results of the processing of planned technological processes of ASW recycling in terms of Enetworks using mathematical processing application, Simulink, three-dimensional model of ASW recycling system is built which allows to visually display the technological process and to compare it with theoretical calculations at the design stage of the TPP and, if necessary, make adjustments. In addition, this approach can be applied to functioning thermal power plants.

\section{References}

1. O. Aksenova, E. Nikolaeva, M. Cehlár, E3S Web of Conferences, 21, 03009 (2017)

2. S.P. Bakhaeva, V.A. Gogolin, I.A. Ermakova, Journal of Mining Science, 52:3, 454-460 (2016)

3. G. A. Kazunina, D. V. Alekseev, Peculiarities of damage cluster distribution in load-ed materials: simulation with probabilistic cellular, 933, 62-65 (2014)

4. B. Morad, T. Horea, Computer-Aided Design, 70, 100-115 (2016)

5. B. Wenlan, Graphical Models, 82, 1-12 (2015) 
6. H. Yang, H. Zhang, Perspective projection, 65, 45-49 (2017)

7. V. M. Zolotukhin, V. A. Gogolin, M. Yu. Yazevich, M.I. Baumgarten, A.V. Dyagileva, IOP Conference Series: Earth and Environmental Science, 1:50 (2017) 